\title{
VPS13D Gene Variant Is Associated with Altered IL-6 Production and Mortality in Septic Shock
}

\author{
Taka-aki Nakada a, b John H. Boyd ${ }^{a}$ James A. Russell ${ }^{a}$ \\ Rosalía Aguirre-Hernández ${ }^{a}$ Mark D. Wilkinson ${ }^{c}$ Simone A. Thair ${ }^{a}$ \\ Emiri Nakada $^{a}$ Melissa K. McConechy ${ }^{a}$ Christopher D. Fjella Keith R. Walley ${ }^{a}$ \\ ${ }^{a}$ Critical Care Research Laboratories, Centre for Heart Lung Innovation, St. Paul's Hospital, University of British \\ Columbia, Vancouver, B.C., Canada; ${ }^{b}$ Department of Emergency and Critical Care Medicine, Chiba University \\ Graduate School of Medicine, Chiba, Japan; ${ }^{C}$ Center for Plant Biotechnology and Genomics, Campus de \\ Montegancedo, Technical University of Madrid, Madrid, Spain
}

\section{Key Words}

VPS13D gene · IL-6 · Severe sepsis · Septic shock ·

Polymorphism · Genome-wide association studies .

Lymphoblastoid cells

\begin{abstract}
Background: Genetic variations contribute to septic shock mortality. To discover a novel locus, we performed in vitro genome-wide association studies (GWAS) and further tested the result in a cohort of septic shock patients. Methods: Two in vitro GWAS using a quantitative trait locus analysis of stimulated IL-6 production in lymphoblastoid cells from 60 individuals of European ancestry were performed. VPS13D rs6685273 was genotyped in European ancestry patients $(\mathrm{n}=498)$. The VPS13D gene was silenced in vitro. Results: Two GWAS using lymphoblastoid cells identified the locus of VPS13D rs6685273 that was significant in the same direction in both GWAS. The VPS13D rs6685273 C allele was associated with increased IL- 6 production. Patients with septic shock who had the VPS13D rs6685273 CC genotype had an increased 28-day mortality $(p=0.023)$ and more organ failure $(p<0.05)$ compared to the CT/TT genotypes. VPS13D in vitro gene silencing in the HeLa cell line increased IL- 6 produc-
\end{abstract}

(C) 2015 S. Karger AG, Basel

1662-811X/15/0075-0545\$39.50/0 tion. Furthermore, the rs6685273 genotype was associated with differential VPS13D splice variant expression. Conclusions: The VPS13D rs6685273 C allele was associated with increased IL- 6 production in vitro. The patients with the VPS13D rs6685273 CC genotype had increased 28-day mortality and increased organ failure. VPS13D appears to regulate IL-6 production.

(c) 2015 S. Karger AG, Basel

\section{Introduction}

Genetic factors substantially contribute to mortality due to infection [1]. Single-nucleotide polymorphisms (SNPs) in known candidate genes in innate immune and inflammatory pathways [2] have been found to be associated with altered clinical outcome of severe sepsis $[3,4]$. However, these discoveries are limited by the selection of known candidate genes. An unbiased approach is required to discover loci in unanticipated genomic regions or genes [3] associated with sepsis outcome.

In a heterogeneous condition such as sepsis, exceedingly large patient cohorts would be required to allow a cryptic genotype-phenotype relationship to be identified

\section{KARGER 125}

E-Mail karger@karger.com www.karger.com/jin 
when millions of possible SNPs are interrogated. An alternative approach is to use a step-wise strategy. Accordingly, we first conducted a derivation genome-wide association study (GWAS) in densely genotyped lymphoblastoid cell lines under cytokine mixture-stimulated conditions designed to simulate severe sepsis [5]. We used IL- 6 production as the primary outcome in this in vitro study because IL-6, among many other possible candidate cytokines, is robustly associated with adverse outcome in septic shock $[6,7]$. To discover novel associations outside of previously considered candidate genes, which are typically regulated by NF- $\kappa \mathrm{B}[8,9]$, we repeated this GWAS with the addition of corticosteroid treatment to modulate NF- $\kappa \mathrm{B}$, again using IL- 6 production as the primary outcome variable. Corticosteroids are a therapeutic option for patients with septic shock, and we wished to detect strong IL- 6 determinants even in the presence of low-dose corticosteroids. We selected only SNPs identified in both GWAS for further consideration. For validation of clinical relevance, we then tested for an association between SNPs identified by this in vitro GWAS and clinical outcome in a large cohort of patients with septic shock [10]. This step-wise approach identified a poorly understood gene associated with septic shock outcome. To test for biological plausibility and to start to understand the mechanism underlying this genotype-phenotype association, we evaluated gene function by in vitro gene silencing and measured splice variant expression by genotype of the involved gene.

\section{Material and Methods}

Treatment of Lymphoblastoid Cells and IL-6 Measurement

Lymphoblastoid cell lines from 60 unrelated individuals of western European ancestry (CEU) genotyped by the HapMap Project (phase II) were used. To simulate an inflammatory response under controlled in vitro conditions, the lymphoblastoid cell lines were stimulated using cytomix $[2.5 \mathrm{ng} / \mathrm{ml}$ each of TNF- $\alpha$, IL- $1 \beta$ and IFN- $\gamma$ (R\&D Systems) and $12.5 \mu \mathrm{M}$ of CpG (Sigma-Aldrich)] for $24 \mathrm{~h}[5,11]$. The primary outcome was IL- 6 concentration in supernatant measured using ELISA (R\&D Systems, sensitivity threshold $0.7 \mathrm{pg} / \mathrm{ml}$ ). To enrich potential results in novel genes not typically involved in canonical NF- $\kappa \mathrm{B}$ signaling, the experiment was repeated with cells incubated with hydrocortisone $24 \mathrm{~h}$ prior to cytomix stimulation. We used $1.45 \mu \mathrm{g} / \mathrm{ml}$ of hydrocortisone based on plasma levels of cortisone in patients with septic shock treated with low-dose hydrocortisone [12]. IL-6 production from 60 lymphoblastoid cell lines in the two conditions were successfully measured and used in the GWAS analysis. Hydrocortisone treatment reduced IL- 6 production by $61.2 \pm 6.5 \%$ in the cytomix-stimulated lymphoblastoid cells $(\mathrm{p}<0.01)$. Additional detail on the methods is provided in an online data supplement.

\section{GWAS Analysis}

The genotypes and locations of SNPs were obtained from the HapMap database (v23a, NCBI Build 36). IL-6 levels were used as the quantitative trait primary outcome. A Wald test without permutation was used to assess statistical significance. False discovery rate (FDR) was used to correct for multiple testing across many SNPs and we further chose an FDR threshold (0.02) of approximately half of the conventional 0.05 because we tested the same hypothesis in 2 separate experiments [13]. PLINK version 1.07 was used for the GWAS analysis.

\section{Severe Sepsis Cohort and Genotyping}

The Vasopressin and Septic Shock Trial was a multicenter, randomized, double-blind, controlled trial evaluating the efficacy of vasopressin versus norepinephrine in septic shock patients [10]. DNA genotyping data were available for 580 (including 498 of European ancestry) of the total sample of 778 patients. Of these, 320 patients had plasma available upon admission. DNA was extracted from buffy coat of discarded blood samples using a QIAamp DNA maxi kit (Qiagen). VPS13D rs6685273 C/T and SORBS2 s4862562 $\mathrm{A} / \mathrm{C}$ were genotyped using an Illumina $1 \mathrm{M}$-Duo DNA chip assay. The research ethics boards of all participating institutions approved this trial and written informed consent was obtained. The research ethics board at the coordinating center (University of British Columbia) approved the genetic analysis.

\section{RNA Interference and Gene Expression of VPS13D}

The HeLa cell line was used because it is a well-characterized cell line with well-developed protocols for successful transfection, rather than lymphoblastoid cells like in the initial analysis. The HeLa cells were transfected with VPS13D small-interfering (si) RNA or negative control siRNA (Invitrogen) using lipofectamine RNAiMAX (Invitrogen) as per the manufacturer's modified instructions. After $24 \mathrm{~h}$ of incubation at $37^{\circ} \mathrm{C}$, the cells were stimulated either with or without TNF- $\alpha(10 \mathrm{ng} / \mathrm{ml})$, and then incubated for an additional $24 \mathrm{~h}$.

Since we could not obtain a VPS13D antibody to reliably detect human VPS13D protein from commercially available antibodies, VPS13D gene expression was measured using quantitative realtime reverse-transcriptase polymerase chain reaction (qRT-PCR) to confirm knockdown of the VPS13D gene by siRNA.

\section{Transcript Variants}

We determined the fraction of transcript variant 1 and variant 2 in 16 lymphoblastoid cells of known VPS13D rs6685273 genotype [CC genotype $(n=8)$; TC genotype $(n=8)$ ] using RT-PCR [14].

\section{Statistical Analysis}

Each experiment was performed in biological triplicate and technical duplicate. For clinical data analysis, the primary outcome variable was 28 -day mortality in patients of European ancestry. We tested for differences by genotype using the Armitage trend test. Replication of this result was also tested for in patients of all ancestries. The secondary outcome was organ dysfunction. We calculated days alive and free of organ dysfunction and organ support (vasopressors, ventilation and renal support) to measure differences in organ dysfunction by genotype (Brussels criteria [10]) during the 28-day study period as previously reported [15]. We used the Mann-Whitney U test for differences in these parameters. 
Table 1. Two GWAS of lymphoblastoid cells identified 2 loci associated with altered IL-6 levels

\begin{tabular}{lllllllll}
\hline & Gene & Chromosome & $\begin{array}{l}\text { Major (minor) } \\
\text { allele }\end{array}$ & $\begin{array}{l}\text { MAF } \\
\text { (HWE p value) }\end{array}$ & $\begin{array}{l}\text { GWAS 1 }^{\mathrm{a}} \\
\text { p value }\end{array}$ & $\begin{array}{l}\text { GWAS 1 } \\
\text { FDR }\end{array}$ & $\begin{array}{l}\text { GWAS 2 }^{\mathrm{b}} \\
\text { p value }\end{array}$ & $\begin{array}{l}\text { GWAS 2 } \\
\text { FDR }\end{array}$ \\
\hline rs6685273 & VPS13D & $1 \mathrm{p} 36.22$ & C (T) & $0.068(0.56)$ & $3.6 \times 10^{-7}$ & 0.019 & $3.5 \times 10^{-7}$ \\
rs4862562 & SORBS2 & $4 \mathrm{q} 35.1$ & A (C) & $0.076(0.26)$ & $2.8 \times 10^{-8}$ & 0.0015 & $8.8 \times 10^{-10}$ & 0.00033 \\
\hline
\end{tabular}

MAF = Minor allele frequency; HWE = Hardy-Weinberg equilibrium; VPS13D = vacuolar protein-sorting 13 homolog D; SORBS2 = sorbin and SH3 domain containing 2.

${ }^{a}$ IL-6 production of lymphoblastoid cells under inflammatory stimulation (cytomix) as a quantitative trait.

b IL-6 production of lymphoblastoid cells in which corticosteroid treatment was added to the inflammatory stimulation.

Plasma IL-6 levels in patients with septic shock were analyzed using log-transformed values. Differences were considered significant using a two-tailed $\mathrm{p}<0.05$. Analyses were performed using SPSS (SPSS, v16, Chicago, Ill., USA) statistical software packages.

\section{Results}

Two GWAS Using Lymphoblastoid Cells Identify Two Loci Associated with Altered IL-6 Levels Including VPS13D rs6685273

We first performed a GWAS using IL-6 production of lymphoblastoid cells (European ancestry, $n=60$ ) under inflammatory stimulation (cytomix) [5] as a quantitative trait. Of 2.3 million common HapMap SNPs considered in this GWAS, we found 421 (69 genes) that were significant protein quantitative trait loci (QTL; FDR $<0.02$ ). We next performed a replication GWAS using the IL-6 production of lymphoblastoid cells in which corticosteroid treatment was added to the inflammatory stimulation of lymphoblastoid cells. We found 2 SNPs, VPS13D rs6685273 and SORBS2 rs4862562, to be significant in the same direction in the 2 GWAS and in the Hardy-Weinberg equilibrium (table 1). The major C allele of VPS13D rs $6685273 \mathrm{C} / \mathrm{T}$ and minor C allele of SORBS2 rs 4862562 A/C were associated with increased IL- 6 production. We next tested these SNPs for the impact on clinically relevant outcomes in septic shock patients.

\section{Patients with Septic Shock Who Had VPS13D}

rs6685273 CC Genotype Had an Increased Mortality

Rate and More Organ Dysfunction

We next tested for the clinical relevance of the 2 significant SNPs from the in vitro GWAS (VPS13D and SORBS2) in a cohort of patients with septic shock. The VPS13D rs6685273 C/T SNP was significantly associated with 28-day mortality [Armitage test: European ancestry $(\mathrm{n}=498), \mathrm{p}=0.023$; all ethnicities $(\mathrm{n}=580), \mathrm{p}=0.0091$ ] and after Bonferroni correction for multiple comparisons (European ancestry, $\mathrm{p}=0.046$; all ethnicities, $\mathrm{p}=0.018$ ). SORBS2 s4862562 was not associated with altered 28-day mortality (European ancestry, $\mathrm{p}=0.84$; all ethnicities, $\mathrm{p}=$ $0.99)$.

The VPS13D rs6685273 genotype frequency in patients of European ancestry in this study cohort was in Hardy-Weinberg equilibrium and similar to genotype frequencies in the HapMap data [CC genotype $(\mathrm{n}=397)$, CT genotype $(n=98)$ and TT genotype $(n=3)]$. Due to a small sample size for the minor homozygote TT genotype $(\mathrm{n}=3)$, we compared CC versus CT + TT genotypes. There were no significant baseline differences in gender or surgical versus medical condition by the genotype of VPS13D rs6685273, but there was a nonsignificant trend for older age in patients with the CC genotype (table 2). At baseline, patients who had the VPS13D rs6685273 CC genotype had a lower $\mathrm{PaO}_{2} / \mathrm{FiO}_{2}$ ratio and a higher creatinine concentration in parallel with a trend to an increased prevalence of chronic respiratory disease and renal failure (table 2). These differences in respiratory and renal function and the higher APACHE II score in the CC patients may have been due to random baseline imbalances or clinical outcomes related to the VPS13D genotype, so an age-adjusted Cox regression test was then conducted, entering without/with chronic organ dysfunction as covariates (online suppl. table E1; for all online suppl. material, see www.karger.com/doi/10.1159/000381265).

Kaplan-Meier survival curves illustrate that patients with the VPS13D rs6685273 CC genotype had a significantly higher mortality rate over the 28-day observation period (fig. 1; online suppl. fig. E1, table E1). Patients with the rs6685273 CC genotype had more organ dysfunction (more cardiovascular dysfunction, vasopressor support, 
Table 2. Baseline characteristic of septic shock patients of European ancestry by VPS13D rs6685273 genotype

\begin{tabular}{|c|c|c|c|}
\hline & TT/TC $(\mathrm{n}=101)$ & $\mathrm{CC}(\mathrm{n}=397)$ & $\mathrm{p}$ value \\
\hline Age, years & $59.3(50.6-71.7)$ & $64.4(51.1-73.6)$ & 0.12 \\
\hline Males, n (\%) & $60(59.4)$ & $241(60.7)$ & 0.81 \\
\hline APACHE II & $24(19-29)$ & $26(22-32)$ & 0.0044 \\
\hline Surgical, n (\%) & $26(25.7)$ & $89(22.4)$ & 0.48 \\
\hline Vasopressin use, n (\%) & $52(51.5)$ & $200(50.4)$ & 0.84 \\
\hline Physiologic dose steroid use, $\mathrm{n}(\%)$ & $54(53.5)$ & $216(54.4)$ & 0.87 \\
\hline \multicolumn{4}{|l|}{ Preexisting conditions, $\mathrm{n}(\%)$} \\
\hline Chronic heart failure & $7(6.9)$ & $33(8.3)$ & 0.65 \\
\hline Chronic pulmonary disease & $14(13.9)$ & $76(19.1)$ & 0.22 \\
\hline Chronic liver disease & $10(9.9)$ & $44(11.1)$ & 0.73 \\
\hline Chronic renal failure & $7(6.9)$ & $42(10.6)$ & 0.27 \\
\hline Chronic corticosteroid use & $20(19.8)$ & $80(20.2)$ & 0.94 \\
\hline \multicolumn{4}{|l|}{ Physiologic variables on day 1} \\
\hline Body temperature, ${ }^{\circ} \mathrm{C}$ & $38.4(37.7-39.1)$ & $38.5(37.6-39.2)$ & 0.79 \\
\hline Heart rate, bpm & $128(111-140)$ & $126(110-140)$ & 0.99 \\
\hline Mean arterial pressure, $\mathrm{mm} \mathrm{Hg}$ & $57(50-63)$ & $55(50-61)$ & 0.31 \\
\hline Heart rate, bpm & $14(10-18)$ & $14(11-18)$ & 0.38 \\
\hline \multicolumn{4}{|l|}{ Laboratory variables on day 1} \\
\hline White blood cell count, $10^{3} / \mathrm{mm}^{3}$ & $15.3(8.2-24.0)$ & $15.8(8.1-21.1)$ & 0.29 \\
\hline Platelet count, $10^{3} / \mathrm{mm}^{3}$ & $152(82-260)$ & $172(96-257)$ & 0.54 \\
\hline $\mathrm{PaO}_{2} / \mathrm{FiO}_{2}, \mathrm{~mm} \mathrm{Hg}$ & $199(161-276)$ & $189(135-244)$ & 0.022 \\
\hline Blood creatinine, $\mu \mathrm{mol} / 1$ & $108(70-190)$ & $153(94-249)$ & 0.0003 \\
\hline Blood lactate, $\mathrm{mmol} / \mathrm{l}$ & $2.1(1.4-3.6)$ & $2.2(1.4-4.4)$ & 0.34 \\
\hline
\end{tabular}

Data are given as the median (interquartile range) for continuous variables. $p$ values were calculated with the use of the Mann-Whitney $U$ test and the $\chi^{2}$ test. APACHE $=$ Acute physiology and chronic health evaluation.

Table 3. Days alive and free of organ dysfunction and organ support in septic shock patients of European ancestry by VPS13D rs6685273 genotype

\begin{tabular}{lccl}
\hline & $\begin{array}{l}\text { TT/TC } \\
(\mathrm{n}=101)\end{array}$ & $\begin{array}{l}\text { CC } \\
(\mathrm{n}=397)\end{array}$ & p value \\
\hline $\begin{array}{l}\text { Days alive and free of organ dysfunction } \\
\text { Cardiovascular }\end{array}$ & & \\
Respiratory & $6(9-17)$ & $3(0-15)$ & 0.072 \\
Renal & $28(13-28)$ & $21(3-28)$ & 0.0014 \\
Hematologic & $27(14-28)$ & $25(7-28)$ & 0.14 \\
Hepatic & $27(11-28)$ & $26(5-28)$ & 0.17 \\
Neurologic & $19(8-26)$ & $16(0-25)$ & 0.0088 \\
Artificial organ support & & & \\
Vasopressor & $22(10-24)$ & $19(0-24)$ & 0.020 \\
Ventilator & $14(1-21)$ & $9(0-20)$ & 0.058 \\
Acute renal & & & \\
replacement therapy & $28(17-28)$ & $25(6-28)$ & 0.0006 \\
\hline
\end{tabular}

Data are denoted as the median (interquartile range) and were calculated for the 28-day study period [15]. The Mann-Whitney U test was used to calculate $\mathrm{p}$ values. renal dysfunction, renal replacement therapy and neurologic dysfunction; table 3). Nonsurvivors had increased plasma IL-6 levels compared to survivors ( $p=0.0010$; fig. 1c). Patients with the CC genotype had numerically greater average plasma IL-6 levels at baseline than the other genotypes, but this difference was not statistically significant (TT vs. TC vs. CC genotype, $p=0.29$; fig. $1 \mathrm{~d}$ ).

\section{VPS13D Gene Silencing Increased IL-6 Production in HeLa Cells}

To determine whether VPS13D alters IL-6 production, we carried out VPS13D gene silencing in HeLa cells using siRNA (fig. 2a) and measured IL-6 levels in the supernatant. Silencing VPS13D significantly increased IL-6 levels in both unstimulated and TNF-stimulated conditions (fig. 2).

\section{VPS13D rs6685273 CC Genotype Is Associated with} Increased Expression of Splice Variant 1

We next tested for potential mechanisms of the VPS13D rs6685273 SNP effects on in vitro and clinical 

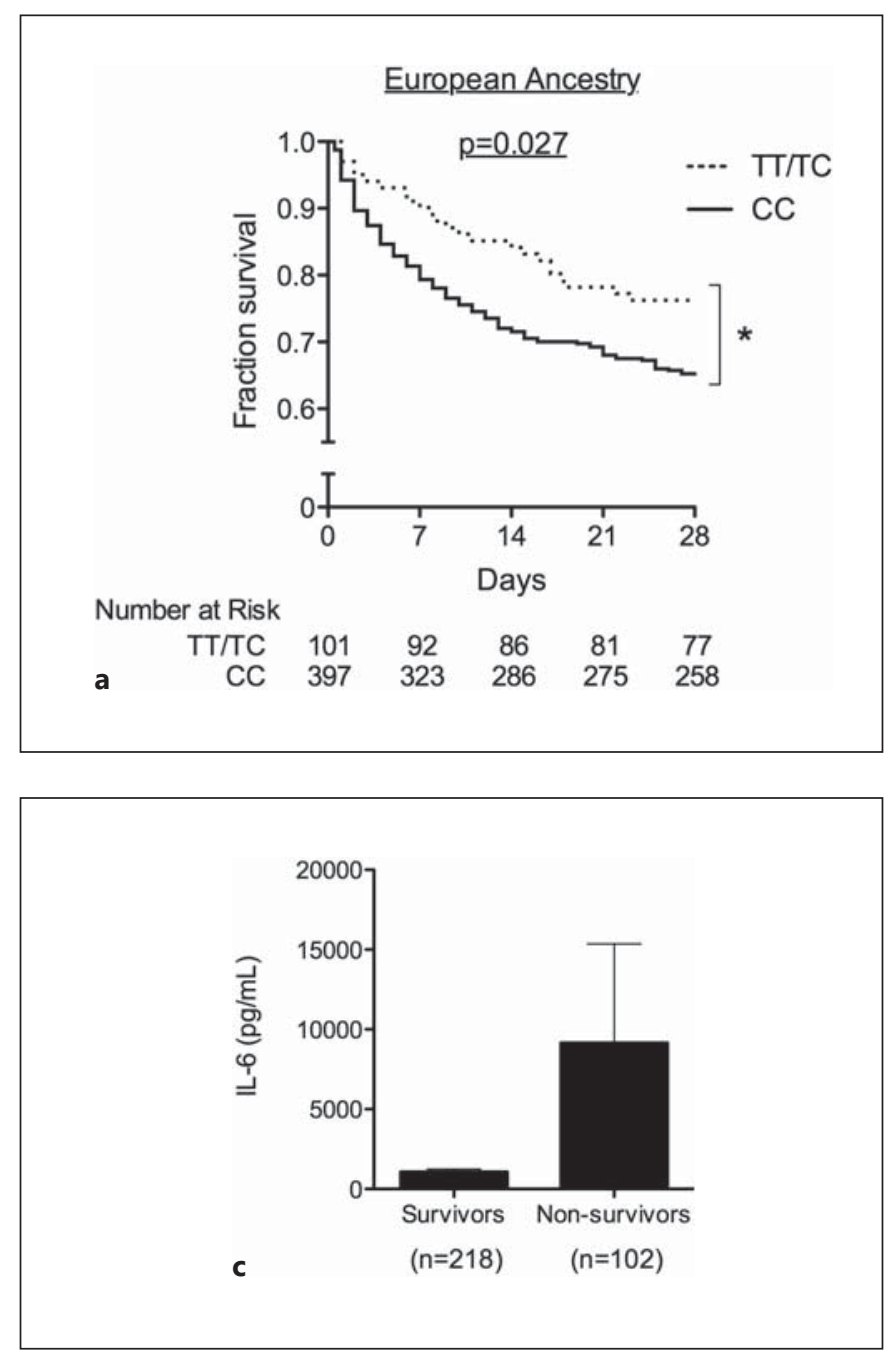

Fig. 1. Survival curves and plasma IL-6 levels in the septic shock patients by the genotype of the VPS13D rs6685273 polymorphism. a, b Patients with the VPS13D rs6685273 CC genotype (solid line) had a significantly increased risk of death over 28 days $[\mathrm{p}=0.027$ (European ancestry), $\mathrm{p}=0.011$ (all ethnicities), TT/TC vs. CC genotype]. The log-rank test was used to calculate $\mathrm{p}$ values. c Plasma IL-6 levels between survivors and nonsurvivors. Nonsurvivors had

phenotypes. Two major transcript variants of VPS13D are documented [14]. The transcript variant 2 differs from transcript variant 1 only by the absence of exon 40, which is close to the VPS13D rs6685273 C/T SNP and lies in the same haplotype block in the CEU HapMap data (fig. 3a). Therefore, we measured the expression of these 2 transcript variants in 16 lymphoblastoid cells of known rs6685372 genotype by RT-PCR [14]. The CC genotype was associated with increased expression of splice variant 1 compared to CT genotype ( $\mathrm{p}=0.034$; fig. $3 \mathrm{~b}$ ).

VPS13D Polymorphisms and Septic Shock
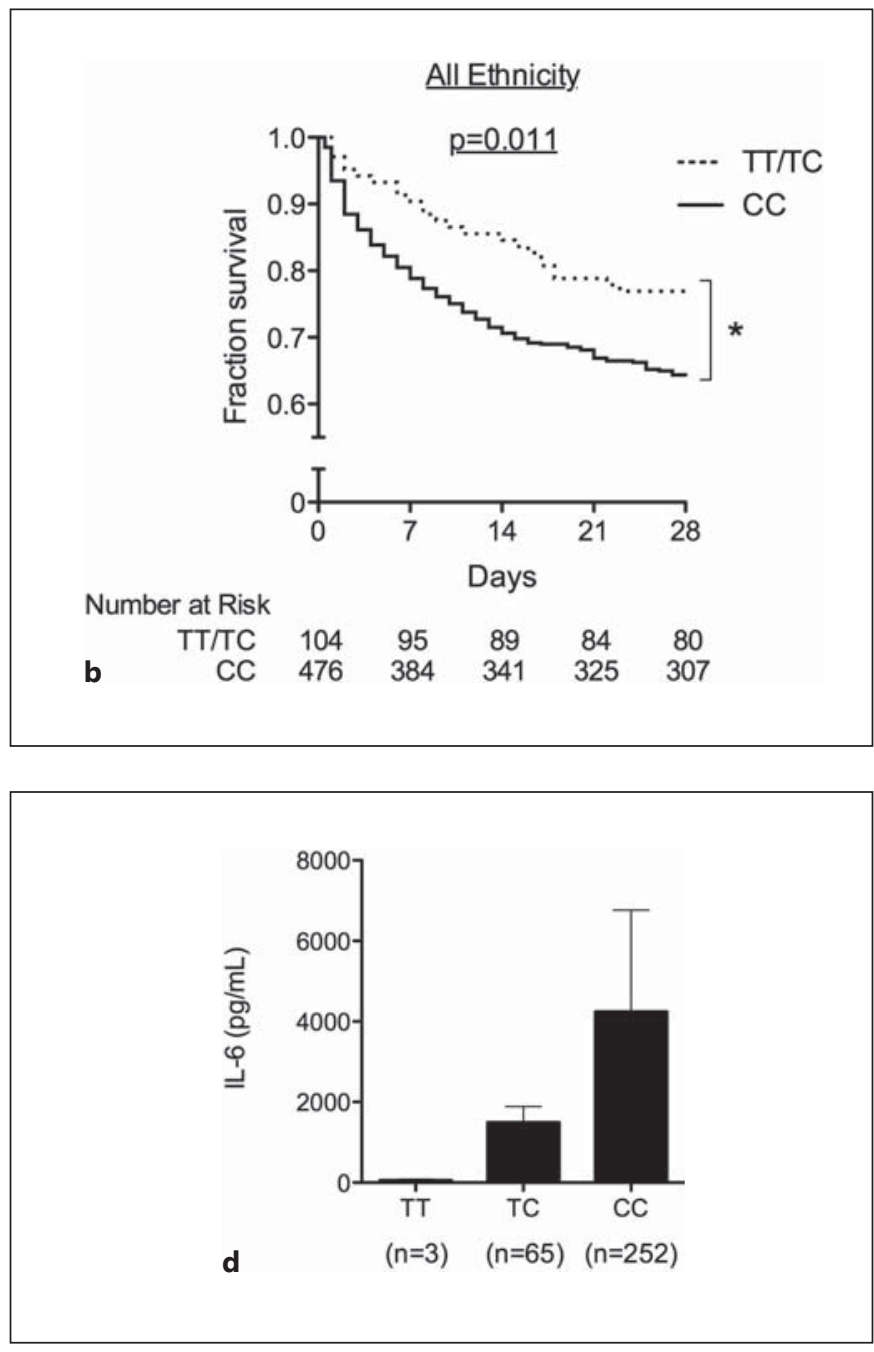

increased plasma IL-6 levels compared to survivors ( $\mathrm{p}=0.0010)$. d Plasma IL-6 levels by VPS13D rs6685273 genotype. There was a nonsignificant trend for higher plasma IL-6 levels in patients with the CC genotype (TT vs. TC vs. CC genotype, $\mathrm{p}=0.26$, one-way ANOVA). Plasma IL-6 levels were log-transformed and analyzed. The Student $t$ test or one-way ANOVA was used to calculate $\mathrm{p}$ values. Data are the mean \pm SEM.

\section{Discussion}

We found that the VPS13D rs6685273 C allele was associated with significantly increased IL- 6 production in 2 separate GWAS studies using lymphoblastoid cells. In addition, the significance of VPS13D rs6685273 was replicated in a cohort of septic shock patients. Patients with the CC genotype of the VPS13D rs6685273 had increased mortality over 28 days and increased organ failure compared with patients who had the CT or TT genotypes. Si- 

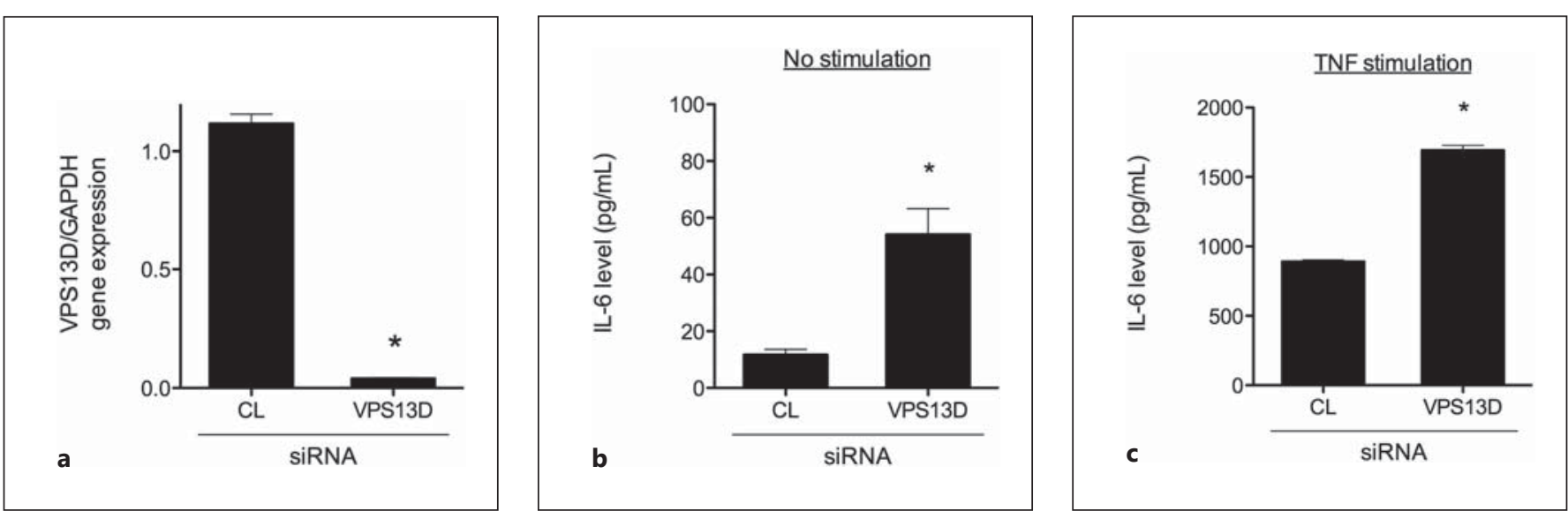

Fig. 2. VPS13D gene silencing increases IL-6 production in HeLa cells. HeLa cells were transfected with siRNA against human VPS13D or a control (CL). a VPS13D gene expression by qRT-PCR demonstrates $96.1 \pm 0.1 \%$ knockdown of VPS13D compared to the

lencing the VPS13D gene in vitro using siRNA increased IL-6 production. The effect of rs6685273, or a genetic variant in linkage disequilibrium, may be due to alteration in relative expression of the splice variants of VPS13D.

The human VPS13D gene is composed of 70 exons covering $280 \mathrm{~kb}$ of genomic DNA. VPS13D is a member of the VPS13 family [14]. VPS13A encodes the protein chorein, and mutated chorein is found in the disease chorea-acanthocytosis [16-18]. Homology between the human VPS13 genes and the yeast Vps13p gene indicates that the sequence has been evolutionarily conserved, and similar genes are found in other eukaryotes including mammals, fruit fly, nematodes and plants [14]. Yeast $V p s 13 p$ protein plays a role in trafficking proteins between the Golgi and endoplasmic reticulum/endosomes [19-21]. Vps proteins interact with SHIP164 as part of a large Golgi-associated retrograde tethering complex which regulates the transfer of membrane proteins to endosomes [22] and possible delivery of these vesicles to the cell surface membrane [20]. Conceivably, VPS13D could be involved in cytokine trafficking and release from innate immune cells [23]. Since human VPS13D encodes a ubiquitin-associated domain, which is found in ubiquitin pathway proteins in the endosomal-lysosomal system [14], the gene function may be involved in the ubiquitination pathway. In addition, since protein-trafficking genes could affect innate immune signaling [24], another possible mechanism is a regulation of subcellular signaling.

We found that the VPS13D rs6685273 C allele was associated with increased IL- 6 production of cells in 2 in control. Cells were then treated for $24 \mathrm{~h}$ with $10 \mathrm{ng} / \mathrm{ml}$ of TNF (c) or without TNF (b). IL-6 levels were measured in supernatant by ELISA. The Student $t$ test was used to calculate $p$ values. Data are the mean \pm SEM. ${ }^{*} \mathrm{p}<0.001$ versus the control. vitro GWAS. Since increased serum IL-6 levels have been associated with increased severity and mortality of septic shock [25], this result raised the possibility that the VPS13D rs6685273 C allele would also be associated with these outcomes in septic shock patients. Indeed, we found that CC genotype patients had more organ failure and a higher 28 -day mortality in a cohort of septic shock patients. To start to understand the potential mechanism of this effect, we found that silencing VPS13D in vitro increased the IL-6 production. To determine whether our identified SNP, VPS13D rs6685273, could potentially be causal, we tested alleles of this SNP for effect on VPS13D splice variant expression which demonstrated by-allele differences. Therefore, VPS13D may function to reduce IL-6 production, which may be beneficial to patients with septic shock. Since the dominant C allele of VPS13D rs6685273 was associated with high sepsis mortality and possibly higher IL-6 levels, the dominant $C$ allele might be associated with less efficiency of IL- 6 repression than the T allele.

VPS13D transcript variants 1 and 2 are highly expressed in a variety of tissues. In most tissues, splice variant 2 , missing exon 40 , is expressed to a greater extent than the full-length splice variant 1 , except in the brain and testis [14]. VPS13D rs6685273 is close to exon 40, is in the same haplotype block, and is associated with altered relative expression of the 2 splice variants. Thus, it is conceivable that rs6685273, or another genetic variant in linkage disequilibrium, alters splice variant expression.

VPS13 genetic polymorphisms have been identified in other GWAS. The VPS13C rs17271305 SNP was identi- 


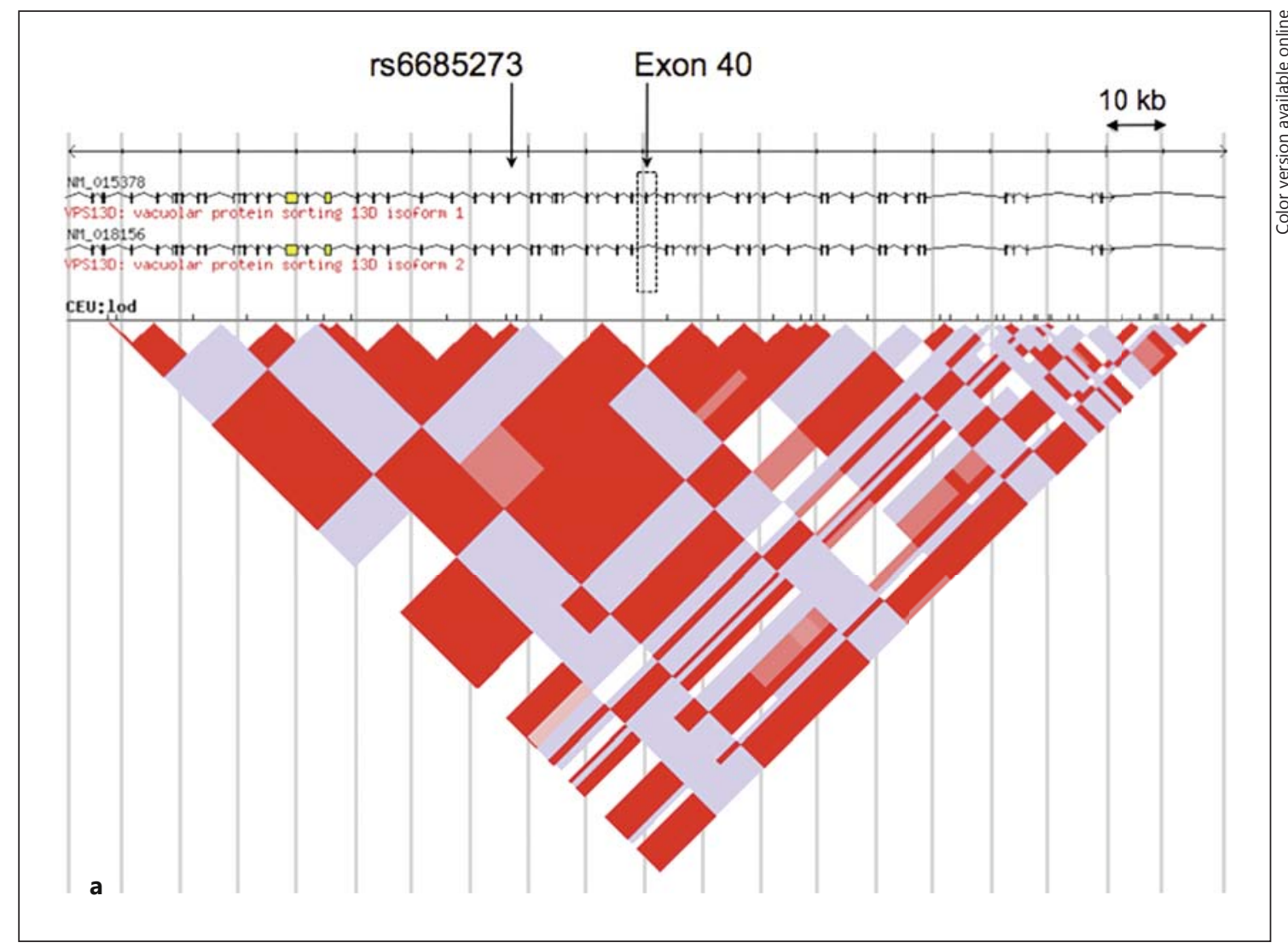

Fig. 3. VPS13D rs6685273 is associated with altered fraction of transcript variants of VPS13D. a Linkage disequilibrium diagram of the VSP13D gene region including VPS13D rs6685273 and VPS13D exon 40. The diagram is from the HapMap European ancestry data and is centered on exon 40 covering a $200-\mathrm{kb}$ gene region. The transcript variant 1 contains exon 40 , and the variant 2 does not contain exon 40. b Fraction of transcript variant 1 by the VPS13D rs6685273 genotype. Transcript variants 1 and 2 were measured in 16 lymphoblastoid cells [CC genotype $(n=8)$ and TC genotype $(n=8)$ ] by RT-PCR using primers that spanned exon 40 and yielded 2 amplicons of different size [transcript variant 1 (286 bp); transcript variant 2 (212 bp)], followed by gel electrophoresis and quantification of band intensity. The CC genotype lymphoblastoid cells had increased the expression of transcript variant 1 compared to the CT genotype $(\mathrm{p}=0.034)$. The Student t test was used to calculate $\mathrm{p}$ values. Data are the mean \pm SEM. ${ }^{*} \mathrm{p}<0.05$.

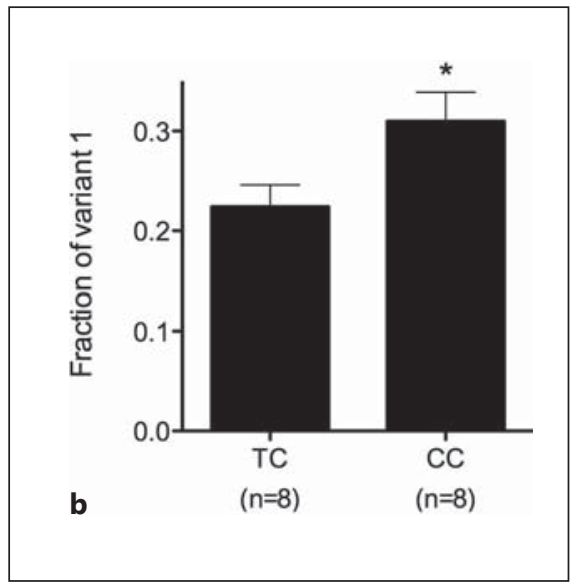

fied in the discovery phase of a GWAS that measured insulin responses to an oral glucose load [26], potentially related to the observation that Vps proteins are involved in the delivery of insulin receptors to the cell surface membrane in yeast [21]. Despite no identification of an overlap of SNPs in our cytomix-stimulated in vitro IL-6 GWAS and previously reported pQTL GWAS using baseline IL-6 in noncritically ill populations $[27,28], V P S 13 D$
SNPs have also been identified in a GWAS of peripheral arterial disease defined by lower limb claudication [29] (specifically rs $235243 \mathrm{G} / \mathrm{T}$ and $\mathrm{rs} 3765337 \mathrm{~T} / \mathrm{G}$ ). Based on HapMap data, the minor allele frequency of rs3765337, marking peripheral arterial disease, is much less than that of rs6685273, the SNP that we have identified. However, it is notable that the risk allele of rs3765337 is always found in a haplotype containing the rs6685273 risk allele. 
The risk allele of rs 3765337 for peripheral arterial disease aligns with the risk allele that we identified to be associated with increased IL- 6 concentration in vitro and increased mortality in septic shock. Thus, VPS13D is a largely unrecognized gene that appears to play an important role in inflammation, possibly by a novel mechanism related to protein trafficking between the Golgi and endosomes.

This study has several limitations. There was an association of the VPS13D rs6685273 SNP with altered IL-6 levels in cells and mortality in septic shock patients, but the cells and patients were of European ancestry, so the findings may be limited to this ancestry. Despite the novel identification of the VPS13D SNP from GWAS using IL-6 production in HapMap lymphoblastoid cells as the primary outcome, QTL analysis using outcomes other than IL-6, its early or late stages such as IL-18 and macrophage migration inhibitory factor or other cells may produce additional candidates or present important hypotheses concerning the mechanism by which VPS13D is associated with mortality in sepsis. In addition, different methods of GWAS analysis including QTL mapping such as interval mapping or with adjustment for age may give additional candidates. While we identified 2 SNPs from 2 GWAS using a stringent FDR threshold rate of $2 \%$, we did not identify marginally significant loci when setting a threshold rate of $3 \%$. Replication of the association of the VPS13D SNP with 28-day mortality and further evaluation of a direct effect of the SNP on plasma IL-6 levels in patients with severe sepsis using independent, larger cohorts would strengthen this study. We demonstrated a significant reduction in VPS13D gene expression by siRNA, but due to the unavailability of human VPS13D antibody, we could not confirm VPS13D knockdown in protein levels. Further in vitro study assessing IL-6 production in VPS13D overexpressing cells or in macrophage or T lymphocyte cell lines to invoke an IL-6 interaction would strengthen our finding of increased IL-6 production in VPS13D knockdown in HeLa cell lines. The significant difference of VPS13D splice variant expression by rs6685273 using gel quantification after RT-PCR in 16 lymphoblastoid cells of known VPS13D rs6685273 genotype was observed in this study. Further studies using different methods including quantitative PCR and larger sample sizes would strengthen this study result. The VPS13D gene is very poorly characterized in human biology and inflammation, and our findings of associations of the VPS13D rs6685273 SNP with altered IL-6 levels and expression of splice variants 1 and 2 do not prove a causal link.

To conclude, the VPS13D rs6685273 C allele was associated with increased IL-6 production in vitro. Patients with the VPS13D rs6685273 CC genotype had increased mortality over 28 days and increased organ dysfunction. VPS13D appears to regulate IL-6 production.

\section{Acknowledgements}

This work was supported by Canadian Institutes of Health Research and partially by a grant-in-aid for young scientists from the Japan Society for the Promotion of Science. T. Nakada is a Canadian Institute of Health Research IMPACT Postdoctoral Fellow. J.H. Boyd is a National Sanitarium Association Scholar.

\section{Disclosure Statement}

No competing interests are disclosed.

\section{References}

$>1$ Sorensen TI, Nielsen GG, Andersen PK, Teasdale TW: Genetic and environmental influences on premature death in adult adoptees. N Engl J Med 1988;318:727-732.

$\checkmark 2$ Cinel I, Opal SM: Molecular biology of inflammation and sepsis: a primer. Crit Care Med 2009;37:291-304.

3 Sutherland AM, Walley KR: Bench-to-bedside review: association of genetic variation with sepsis. Crit Care 2009;13:210.

$\checkmark 4$ Brouwer MC, de Gans J, Heckenberg SG, Zwinderman $\mathrm{AH}$, van der Poll T, van de Beek D: Host genetic susceptibility to pneumococcal and meningococcal disease: a systematic review and meta-analysis. Lancet Infect Dis 2009;9:31-44.
5 Nakada TA, Russell JA, Boyd JH, AguirreHernandez R, Thain KR, Thair SA, Nakada E, McConechy M, Walley KR: Beta2-adrenergic receptor gene polymorphism is associated with mortality in septic shock. Am J Respir Crit Care Med 2010;181:143-149.

6 Abraham E, Glauser MP, Butler T, Garbino J, Gelmont D, Laterre PF, Kudsk K, Bruining HA, Otto C, Tobin E, Zwingelstein C, Lesslauer W, Leighton A: p55 tumor necrosis factor receptor fusion protein in the treatment of patients with severe sepsis and septic shock. A randomized controlled multicenter trial. Ro 45-2081 Study Group. JAMA 1997;277:1531-1538.
7 Yende S, D’Angelo G, Kellum JA, Weissfeld L, Fine J, Welch RD, Kong L, Carter M, Angus DC: Inflammatory markers at hospital discharge predict subsequent mortality after pneumonia and sepsis. Am J Respir Crit Care Med 2008;177:1242-1247.

8 Yamauchi S, Ito H, Miyajima A: Ikappabeta, a nuclear IkappaB protein, positively regulates the NF-kappaB-mediated expression of proinflammatory cytokines. Proc Natl Acad Sci USA 2010;107:11924-11929.

$>9$ Li Q, Verma IM: NF-kappaB regulation in the immune system. Nat Rev Immunol 2002;2: $725-734$. 
$\longrightarrow 10$ Russell JA, Walley KR, Singer J, Gordon AC, Hebert PC, Cooper DJ, Holmes CL, Mehta S, Granton JT, Storms MM, Cook DJ, Presneill JJ, Ayers D: Vasopressin versus norepinephrine infusion in patients with septic shock. N Engl J Med 2008;358:877-887.

-11 Farley KS, Wang L, Mehta S: Septic pulmonary microvascular endothelial cell injury: Role of alveolar macrophage NADPH oxidase. Am J Physiol Lung Cell Mol Physiol 2009;296:L480-L488.

-12 Keh D, Boehnke T, Weber-Cartens S, Schulz C, Ahlers O, Bercker S, Volk HD, Doecke WD, Falke KJ, Gerlach H: Immunologic and hemodynamic effects of 'low-dose' hydrocortisone in septic shock: a double-blind, randomized, placebo-controlled, crossover study. Am J Respir Crit Care Med 2003;167: 512-520.

13 Storey JD, Tibshirani R: Statistical significance for genome-wide studies. Proc Natl Acad Sci USA 2003;100:9440-9445.

14 Velayos-Baeza A, Vettori A, Copley RR, Dobson-Stone C, Monaco AP: Analysis of the human VPS13 gene family. Genomics 2004;84: 536-549.

15 Walley KR, Russell JA: Protein C-1641 AA is associated with decreased survival and more organ dysfunction in severe sepsis. Crit Care Med 2007;35:12-17.

16 Rampoldi L, Dobson-Stone C, Rubio JP, Danek A, Chalmers RM, Wood NW, Verellen C, Ferrer X, Malandrini A, Fabrizi GM, Brown R, Vance J, Pericak-Vance M, Rudolf G, Carre S, Alonso E, Manfredi M, Nemeth AH, Monaco AP: A conserved sorting-associated protein is mutant in chorea-acanthocytosis. Nat Genet 2001;28:119-120.
17 Scheid R, Bader B, Ott DV, Merkenschlager A, Danek A: Development of mesial temporal lobe epilepsy in chorea-acanthocytosis. Neurology 2009;73:1419-1422.

18 Ueno S, Maruki Y, Nakamura M, Tomemori Y, Kamae K, Tanabe H, Yamashita Y, Matsuda S, Kaneko S, Sano A: The gene encoding a newly discovered protein, chorein, is mutated in chorea-acanthocytosis. Nat Genet 2001:28:121-122.

19 Brickner JH, Fuller RS: SOI1 encodes a novel, conserved protein that promotes TGN-endosomal cycling of Kex2p and other membrane proteins by modulating the function of two TGN localization signals. J Cell Biol 1997;139: 23-36.

20 Nakanishi H, Suda Y, Neiman AM: ERV14 family cargo receptors are necessary for ER exit during sporulation in Saccharomyces cerevisiae. J Cell Sci 2007;120:908-916.

21 Zhang B, Chang A, Kjeldsen TB, Arvan P: Intracellular retention of newly synthesized insulin in yeast is caused by endoproteolytic processing in the Golgi complex. J Cell Biol 2001;153:1187-1198.

22 Otto GP, Razi M, Morvan J, Stenner F, Tooze SA: A novel syntaxin 6-interacting protein, SHIP164, regulates syntaxin 6-dependent sorting from early endosomes. Traffic 2010; 11:688-705.

23 Lacy P, Stow JL: Cytokine release from innate immune cells: association with diverse membrane trafficking pathways. Blood 2011;118: 9-18.

24 De Arras L, Yang IV, Lackford B, Riches DW, Prekeris R, Freedman JH, Schwartz DA, Alper $S$ : Spatiotemporal inhibition of innate immunity signaling by the Tbcld23 RAB-GAP. J Immunol 2012;188:2905-2913.
25 Oberholzer A, Souza SM, Tschoeke SK, Oberholzer C, Abouhamze A, Pribble JP, Moldawer LL: Plasma cytokine measurements augment prognostic scores as indicators of outcome in patients with severe sepsis. Shock 2005;23:488-493.

26 Saxena R, Hivert MF, Langenberg C, et al: Genetic variation in GIPR influences the glucose and insulin responses to an oral glucose challenge. Nat Genet 2010;42:142-148.

27 Shah T, Zabaneh D, Gaunt T, Swerdlow DI, Shah S, Talmud PJ, Day IN, Whittaker J, Holmes MV, Sofat R, Humphries SE, Kivimaki M, Kumari M, Hingorani AD, Casas JP: Gene-centric analysis identifies variants associated with interleukin-6 levels and shared pathways with other inflammation markers. Circ Cardiovasc Genet 2013;6:163-170.

28 Naitza S, Porcu E, Steri M, Taub DD, Mulas A, Xiao X, Strait J, Dei M, Lai S, Busonero F, Maschio A, Usala G, Zoledziewska M, Sidore C, Zara I, Pitzalis M, Loi A, Virdis F, Piras R, Deidda F, Whalen MB, Crisponi L, Concas A, Podda C, Uzzau S, Scheet P, Longo DL, Lakatta E, Abecasis GR, Cao A, Schlessinger D, Uda M, Sanna S, Cucca F: A genome-wide association scan on the levels of markers of inflammation in Sardinians reveals associations that underpin its complex regulation. PLoS Genet 2012;8:e1002480.

29 Koriyama H, Nakagami H, Katsuya T, Sugimoto K, Yamashita H, Takami Y, Maeda S, Kubo M, Takahashi A, Nakamura Y, Ogihara T, Rakugi H, Kaneda Y, Morishita R: Identification of evidence suggestive of an association with peripheral arterial disease at the OSBPL10 locus by genome-wide investigation in the Japanese population. J Atheroscler Thromb 2010;17:1054-1062. 